\title{
INFLUENCE OF ROLLING TEMPERATURE ON THE PERFECTION DEGREE OF RECRYSTALLIZATION CUBE TEXTURE IN NICKEL
}

\author{
B. K. SOKOLOV*, I. V. GERVASYEVA, D. P. RODIONOV, \\ Yu. V. KHLEBNIKOVA, I. N. STEPANOVA and D. V. DOLGIH \\ Instytite of Metal Physics, Russian Academy of Sciences, \\ 18 Kovalevskaya str. 620219 Ekaterinburg, Russia
}

(Received 10 November 2000)

The effect of the rolling temperature on the deformation texture and the perfection degree of a cube texture in pure-nickel thin tape were investigated. The kinetics of primary recrystallization was studied on samples that had undergone rolling at different temperatures and the temperature of the onset of secondary recrystallization was determined. Regularities of the structure formation in the samples are discussed. It is established that the cube texture with the maximum sharpness is produced in the samples rolled at room temperature.

Keywords: Nickel tape; Rolling temperature; Cube texture

\section{INTRODUCTION}

Application of a thin nickel tape as a substrate for the hightemperature superconductor $\mathrm{YBa}_{2} \mathrm{Cu}_{3} \mathrm{O}_{7-\delta}$ has lately stimulated increasing interest in creation of a strong cube texture in pure nickel. The value of the critical transport current of a superconductor was shown to depend on the perfection degree of its crystallographic texture, which, in turn, is controlled by the perfection degree of the cube texture of the nickel substrate (Wu et al., 1994; Goyal et al., 1996;

\footnotetext{
*Corresponding author. Fax: (3432) 74 5244, e-mail: sokolov@imp.uran.ru
} 
Norton et al., 1996). Therefore, all the researches were aimed at ascertainment of the possibilities of creation of a strong cube texture in thin nickel tapes (Specht et al., 1998; De Boer et al., 1999; Gervasyeva et al., 2000). Thus, in (Gervasyeva et al., 2000) in a $115 \mu \mathrm{m}$-thick tape of $99.9 \%$-purity nickel, a texture was produced that had a fraction of the cube component of $96 \%$ with the in-rolling-plane scattering of not more than $8^{\circ}$ and that in the plane of longitudinal section, $10^{\circ}$.

In (Makita, Hanada and Izumi, 1988), an assumption was made that to enhance the cube recrystallization texture in nickel, rolling should be performed at temperatures higher than room temperature.

In order to search for the possibilities of increasing the perfection degree for the cube texture in pure nickel, we studied the influence of the rolling temperature on the recrystallization texture evolution. Another object of this work was elucidation of the mechanism of the cube texture formation upon recrystallization in fcc materials, which, nowadays, is still not clear enough.

\section{EXPERIMENTAL}

Vacuum nickel of purity not less than $99.9 \%$ was used. Ingots $0.5 \mathrm{~kg}$ in weight were molten in argon atmosphere. Part of every ingot with a pipe was removed. Billets were forged at temperatures of $800-1000^{\circ} \mathrm{C}$ to rods with $6 \mathrm{~mm}$ edges and then were ground to dimensions $5.9 \times 5.9 \mathrm{~mm}$. Hot-forged billets had a coarse-grained structure inhomogeneous in grain size. To produce initial fine grains, the billets were rolled at room temperature into strips $3.45 \mathrm{~mm}$ thick, the deformation degree being $43 \%$, and were annealed at $600^{\circ} \mathrm{C}$ for $2 \mathrm{~h}$. Such a treatment resulted in a homogeneous fine-grained structure with an average grain size of about $35 \mu \mathrm{m}$.

Part of the produced fine-grained strips $80-100 \mathrm{~mm}$ long were rolled to a thickness of $100 \mu \mathrm{m}$ (deformation degree $97 \%$ ) at liquidnitrogen temperature (mode 1), another part, at room temperature (mode 2), and the rest strips, at $200^{\circ} \mathrm{C}$ (mode 3).

The strips treated by mode 1 were cooled in liquid nitrogen, rolled for $1-2 \mathrm{~s}$, and cooled again. The number of rolling passes was $20-25$. For mode 3 treatment, strips were heated to $200^{\circ} \mathrm{C}$ in the furnace that was mounted directly on the rolling mill and, just after heating, were 
rolled. The interval of heating a strip in the furnace between the rolling runs was 1-10 min and decreased with thinning strips. In the course of rolling, the strips got elongated and were cut into tapes not more than $80 \mathrm{~mm}$ long in order that their exposure to rolling did not exceed $1-2 \mathrm{~s}$.

After deformation, the specimens were annealed at temperatures $250 ; 400 ; 500 ; 600 ; 700 ; 800 ; 900 ; 950 ; 1000 ; 1050$ and $1100^{\circ} \mathrm{C}$. At every above temperature the samples were held for $1 \mathrm{~h}$. Part of the samples were annealed in a salt bath at a temperature of $800^{\circ} \mathrm{C}$ with an exposure of $2 \mathrm{~min}$. The heating rate was about $300^{\circ} \mathrm{C} / \mathrm{s}$.

Metallographic studies were performed on a light microscope "EPYTIP". To open up microstructures of the deformed and annealed specimens, etching was employed by a mixture of concentrated acids $\mathrm{HCl}, \mathrm{H}_{3} \mathrm{PO}_{4}$, and $\mathrm{HNO}_{3}$ with addition of $30-40 \% \mathrm{H}_{2} \mathrm{O}_{2}$ at room temperature.

Thin foils were investigated on a transmission electron microscope JEM-200CX at an accelerating voltage of $200 \mathrm{kV}$ by conventional techniques. Foils were cut parallel to the rolling plane.

To determine the deformation and recrystallization textures, incomplete pole figures $\{111\},\{200\},\{220\}$ and $\{311\}$ were measured by the "reflection" Schulz method to $\alpha=65^{\circ}$. From the specimen surface coinciding with the rolling plane a layer of either 5 or $25 \mu \mathrm{m}$ thick was removed by etching. In the first case, the texture was studied on the specimen surface and in the other case, in subsurface layer. Pole figures were measured with a step of $5^{\circ}$ with $\mathrm{Co}-\mathrm{K}_{\alpha}$ radiation. Study of the texture of the deformed specimens was carried out by analyzing the orientation distribution function (ODF) by the Bunge method and the volume fractions of certain texture components. The volume fraction was calculated with scattering of $\pm 10^{\circ}$. ODF was calculated from four incomplete pole figures with a number of terms of series expansion 22 . The recrystallization textures were analyzed using pole figures $\{111\}$ constructed for the same levels of average pole density. The lowest level in every pole figure was taken equal to the average pole density unit in order to determine if there exist very weak texture components. A maximal value of pole density is indicated on every pole figure.

To determine the texture sharpness, the halfwidth of $\{200\}$ maxima was analyzed upon rotating specimens around the rolling direction 
RD (a spread along TD) and transverse direction TD (a spread along $\mathrm{RD})$. Another characteristic of the cube texture perfection is its percentage. To determine it, the relative fraction of components, including the ideal cube orientation and that deviating from the cube one within $10^{\circ}$, was calculated.

\section{RESULTS}

The rolling texture in nickel can be described by superposition of orientations, whose ODF in the Euler angles is depicted by the texture "tube". This texture tube contains the ideal limited components $\{112\}\langle 111\rangle-\mathrm{C} ;\{123\}\langle 634\rangle-\mathrm{S}$ and $\{011\}\langle 211\rangle$-B. The deformation texture in fcc metals is usually described by these ideal components; therefore, in what follows we shall give quantitative data for these orientations, despite the fact that the real textures include other components as well.

Figure 1 shows ODF sections for nickel rolled at different temperatures. The rolling texture measured from the surface layer (Figs. 1a-c) after all rolling modes contains main limited ideal components which feature the rolling texture in fcc metals with a high stacking fault energy. The volume fraction of the components is presented in Table I.

On the sample surface the strongest component is $\{123\}\langle 634\rangle$, the weaker ones are $\{110\}\langle 112\rangle$ and $\{112\}\langle 111\rangle$. All the textures include the $\{441\}\langle 118\rangle$-type component detected in (Gervasyeva et al., 2000). The texture state in the samples rolled at $200^{\circ} \mathrm{C}$ essentially differs; namely, the volume fraction of the main components is decreased and there is a strong component $\{110\}\langle 011\rangle$ (see Fig. 1c) which was absent in the rolling textures after the mode 1 and 2 treatments.

It should be noted that the sum of volume fractions of the rollingtexture main components on the sample surface is small. It changes from $17 \%$ (in the mode 3 samples) to $30 \%$ (the mode 1 ). Small volume fractions may point to the texture scattering on the sample surface. Removing the $25 \mu \mathrm{m}$-thick layer from the sample surface leads to the texture changes, especially essential for the samples rolled at $200^{\circ} \mathrm{C}$ (Figs. 1d-f). The volume fraction of the main component increases. As follows from Table I, the strongest component is $\{110\}\langle 112\rangle$. The volume fraction of three main components of the rolling texture 
significantly increases and amounts to $55 \%$ in the samples rolled at room temperature; $50 \%$ after warm rolling; and $40 \%$ in the samples treated in liquid nitrogen. The component $\{100\}\langle 011\rangle$ is no longer detected in the texture of the samples rolled at $200^{\circ} \mathrm{C}$ (Fig. 1f). This component is inherent solely in the surface layer of the samples.

The structure of a deformed metal is banded. Bands extended parallel to the rolling direction correspond not only to the contours of

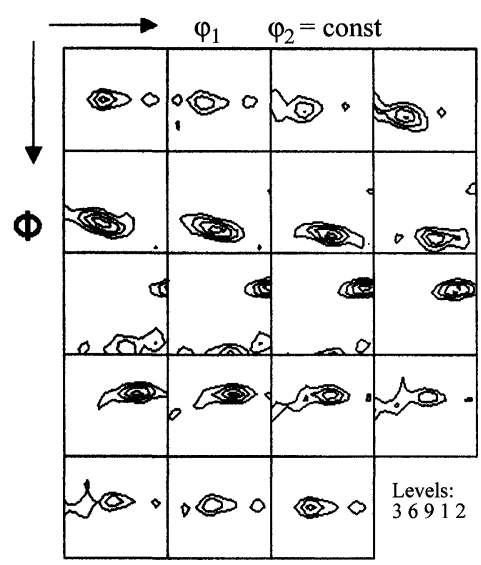

(a)

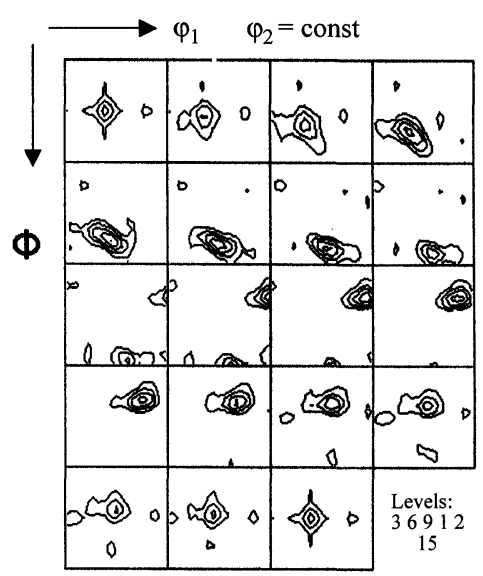

(b)

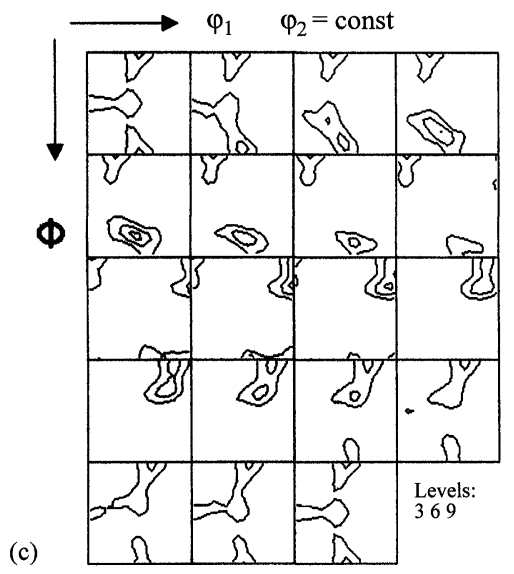

FIGURE 1 ODF sections for the samples after rolling at temperatures: a, d$\left(-196^{\circ} \mathrm{C}\right) ; \mathrm{b}, \mathrm{e}-$ room temperature; $\mathrm{c}, \mathrm{f}-200^{\circ} \mathrm{C} ; \mathrm{a}, \mathrm{b}, \mathrm{c}$-surface texture; $\mathrm{d}$, e, fsubsurface layer texture; $\mathrm{g}$-main limited components of the rolling texture. 


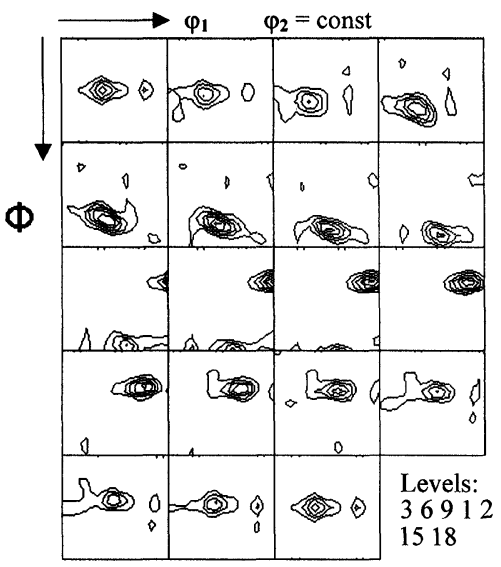

(d)

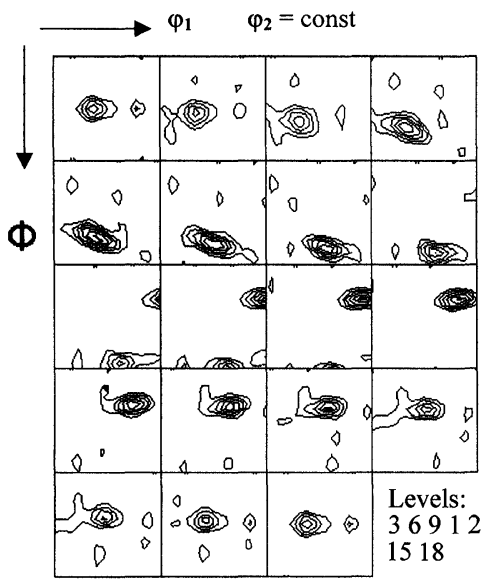

(f)

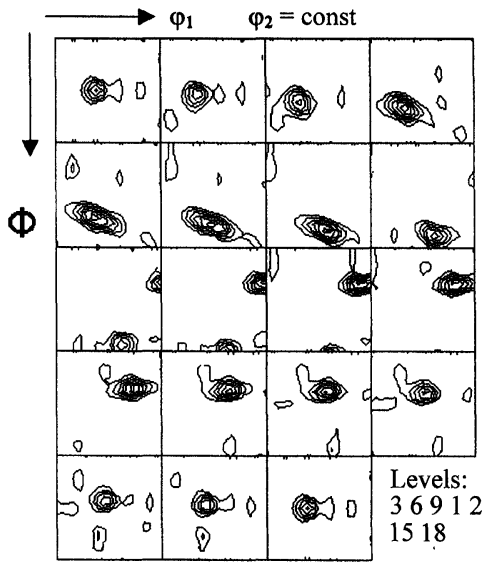

(e)

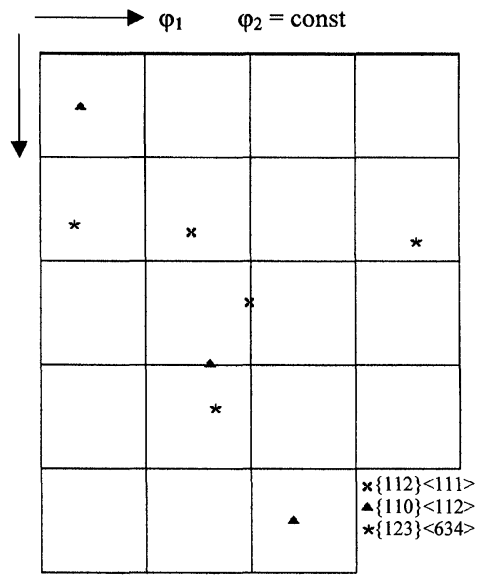

(g)

FIGURE 1 (Continued).

TABLE I Volume fraction of the texture components $\left( \pm 10^{\circ}\right)$ on the surface and subsurface layers of samples, \%

\begin{tabular}{lcccc}
\hline Rolling & \multicolumn{4}{c}{ Texture components } \\
\cline { 2 - 5 } temperature, ${ }^{\circ} \mathrm{C}$ & $\{123\}\langle 634\rangle$ & $\{112\}\langle 111\rangle$ & $\{110\}\langle 112\rangle$ & $\{441\}\langle 118\rangle$ \\
\hline-196 & $14,7(14,8)$ & $5,5(9,0)$ & $10,8(16,4)$ & $1,9(6,0)$ \\
20 & $13,7(19,0)$ & $4,6(12,4)$ & $8,7(22,9)$ & $2,4(2,6)$ \\
200 & $8,2(16,8)$ & $3,1(10,1)$ & $5,8(22,5)$ & $3,1(3,2)$ \\
\hline
\end{tabular}

Note: In brackets there are shown the volume fractions of components in samples at a distance of $25 \mu \mathrm{m}$ from the surface. 
individual deformed grains but to the deformation bands that are formed because of the grain division. This is evidenced by the fact that the average bandwidth is essentially less than the average size of initial grains. Thus, in Figure 2 a microphotograph of the sample treated by mode 2 is shown. The average size of initial grains in the sample was $35 \mu \mathrm{m}$. The average width of the bands after deformation makes up $19 \mu \mathrm{m}$. Taking into account the sample widening of about $6 \%$ one can make the conclusion that every grain is divided into 2 deformation bands. Judging from the microstructure, the boundaries between the deformation bands (transition bands) can hardly be distinguished from the grain boundaries. It follows also from Figure 2 that there are also shear bands in the transverse direction. Microstructure of the samples treated by mode 2 does not differ from the above considered.

The electron microscopy investigation of the foils prepared from the deformed samples revealed that in all cases cellular dislocation structure was formed. After rolling at room temperature the average cell size was equal to $0.2-0.3 \mu \mathrm{m}$. The cells have an elongated shape. Rolling at $-196^{\circ} \mathrm{C}$ results in the formation of narrow bands with a

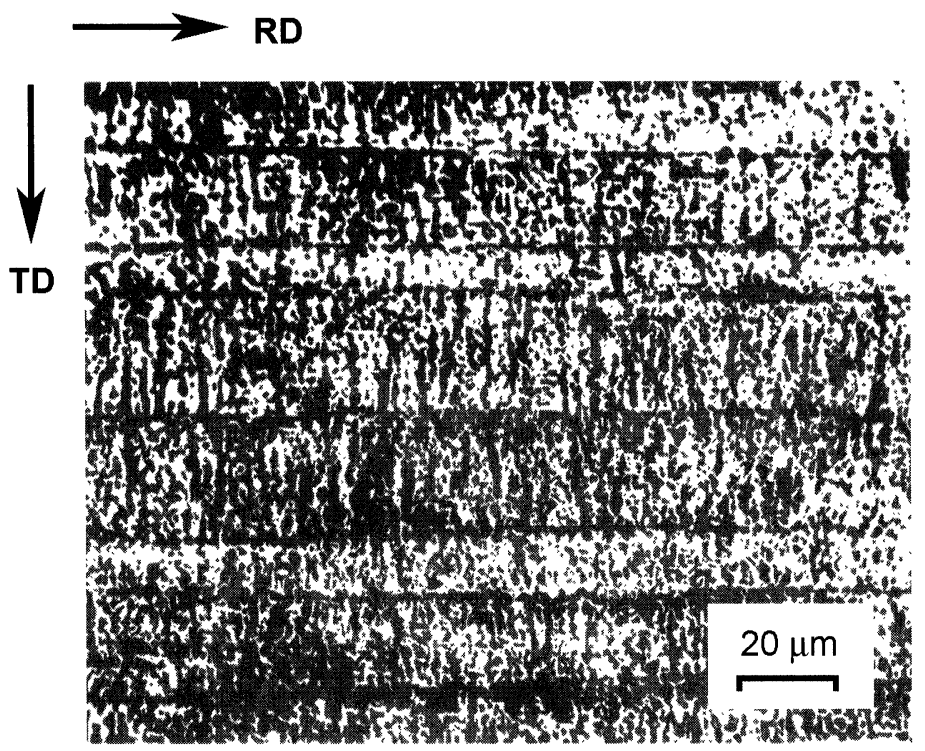

FIGURE 2 Banded microstructure of the sample rolled at room temperature. 
high dislocation density near which the cells have somewhat larger size (Fig. 3).

After the mode 3 treatment the banded microstructure is pronounced less clearly (Fig. 4). Boundaries of the bands located parallel to the rolling direction look cut. Inside the band, a substructure is revealed.

Electron-microscopy pattern of the samples subject to warm rolling also has peculiarities (Fig. 5). The structure is very inhomogeneous. The dislocation clouds are distinctly seen. The cells formed have a larger size (up to $1 \mu \mathrm{m}$ and more); they are virtually free of dislocations. Such cells often have distinct boundaries that may serve as potential recrystallization centers. These cells more often emerge near the extended structure areas that have an increased dislocation density.

Annealing of the rolled samples leads to the recrystallization development in them. Nevertheless the fact that the potential centers of recrystallization in the warm-rolled samples have already formed in the course of deformation, their development proceeds slowly. This is evidenced by the pole figure $\{111\}$ measured after annealing at $600^{\circ} \mathrm{C}$ (Fig. 6a). In the samples treated by mode 3 the texture maxima $\{100\}\langle 001\rangle$ are absent, whereas after the same annealing of the samples treated by modes 1 and 2 they are quite intense. As follows from the

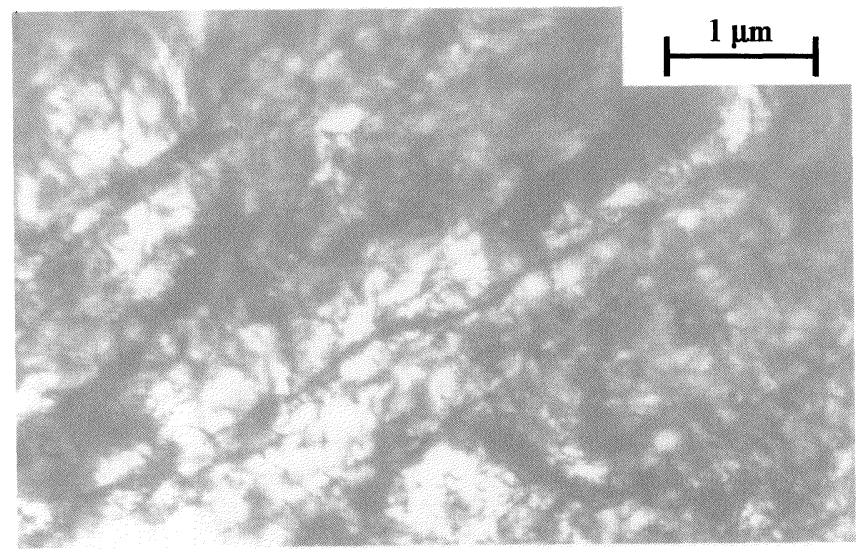

FIGURE 3 Electron-microscopy pattern of the sample structure after rolling at $-196^{\circ} \mathrm{C}$. 


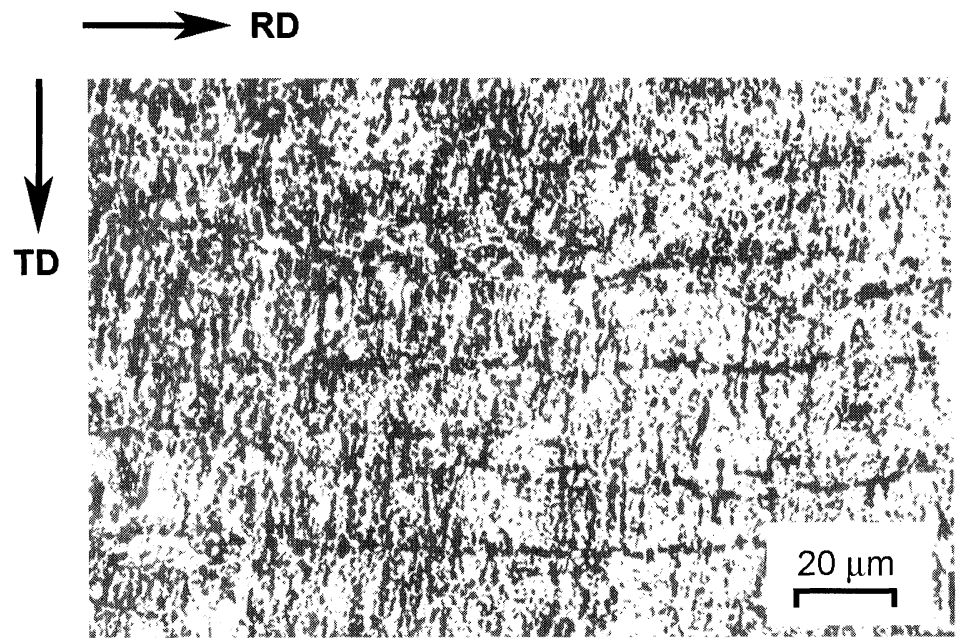

FIGURE 4 Banded microstructure of the sample rolled at $200^{\circ} \mathrm{C}$.

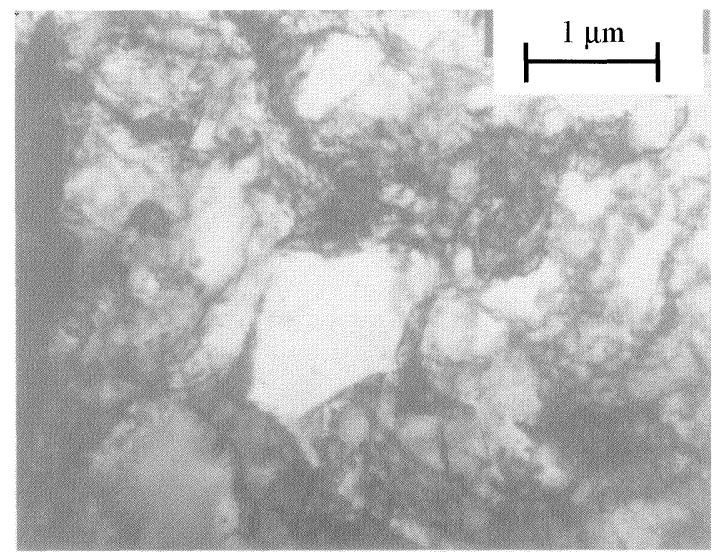

FIGURE 5 Electron-microscopy pattern of the sample structure after rolling at $200^{\circ} \mathrm{C}$.

plot (Fig. 7), the volume fraction of the cube texture in the latter cases makes up 50 and $42 \%$, respectively. In the warm-rolled samples the recrystallization proceeds with a strong retardation, compared to this process in the other samples, at higher annealing temperatures as well.

The appearance of the pole figures suggests that the cube orientation is developing by absorbing the matrix with orientations remarkably 


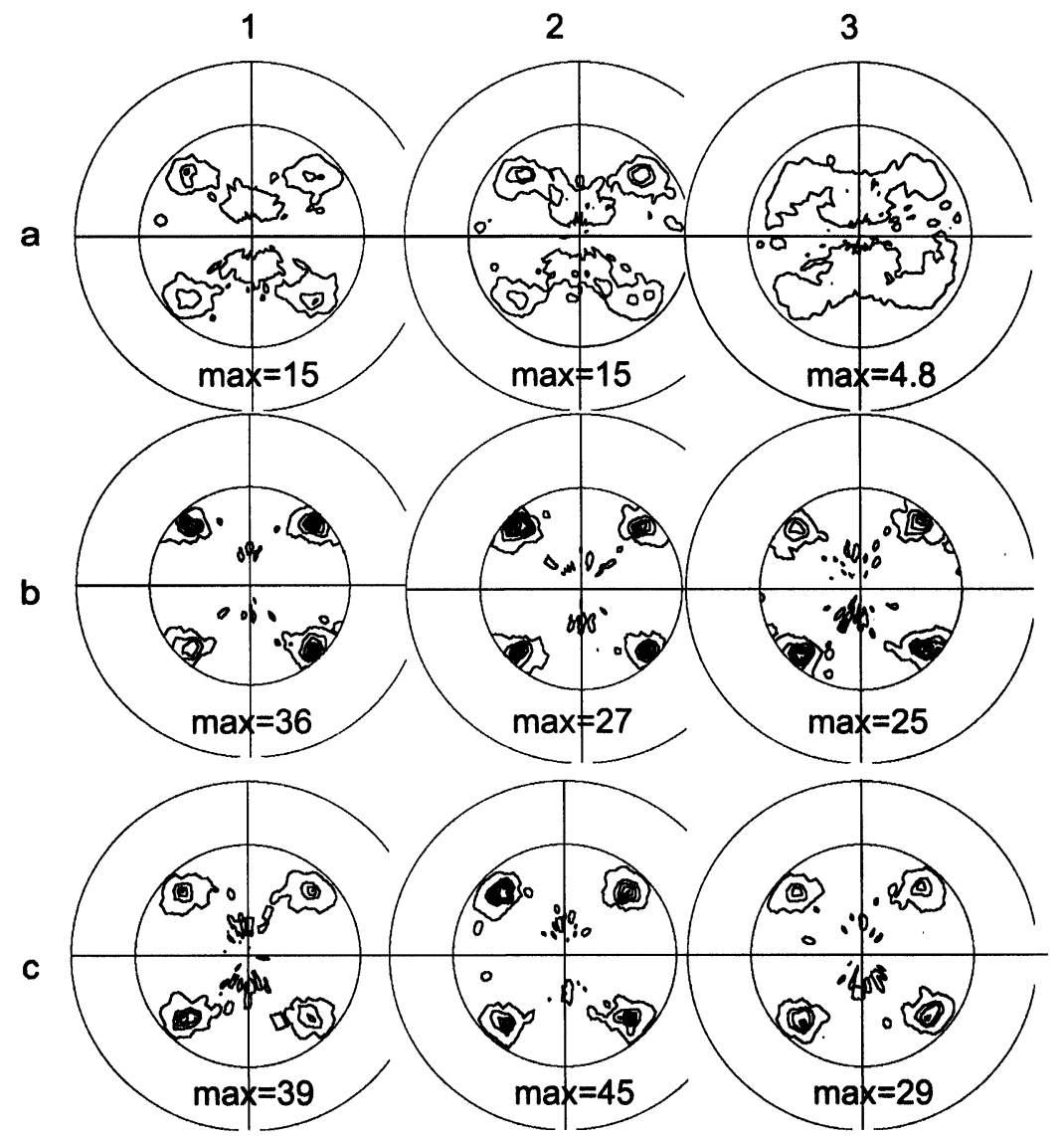

FIGURE 6 Pole figures $\{111\}$ after different-mode rolling (1,2 and 3$)$ and annealing at temperatures: $\mathrm{a}-600^{\circ} \mathrm{C} ; \mathrm{b}-900^{\circ} \mathrm{C}$; and $\mathrm{c}-1000^{\circ} \mathrm{C}$.

declined from $\{100\}\langle 001\rangle$. However, the components close to $\{112\}\langle 111\rangle$ are absorbed in the last turn. The above orientation can be obtained from $\{100\}\langle 001\rangle$ by rotating about the $\langle 133\rangle$-type axis through an angle of about $58^{\circ}$. Among the unabsorbed components the one $\{212\}\langle 122\rangle$ is preserved which is twinned relative to the cubic one (rotation about $\langle 111\rangle$ through $60^{\circ}$ ).

In the course of accelerated recrystallization (annealing of the samples in a salt bath) the cube texture component also develops preferably, which is most pronounced in the samples rolled at room temperature (mode 2 in Fig. 8). 


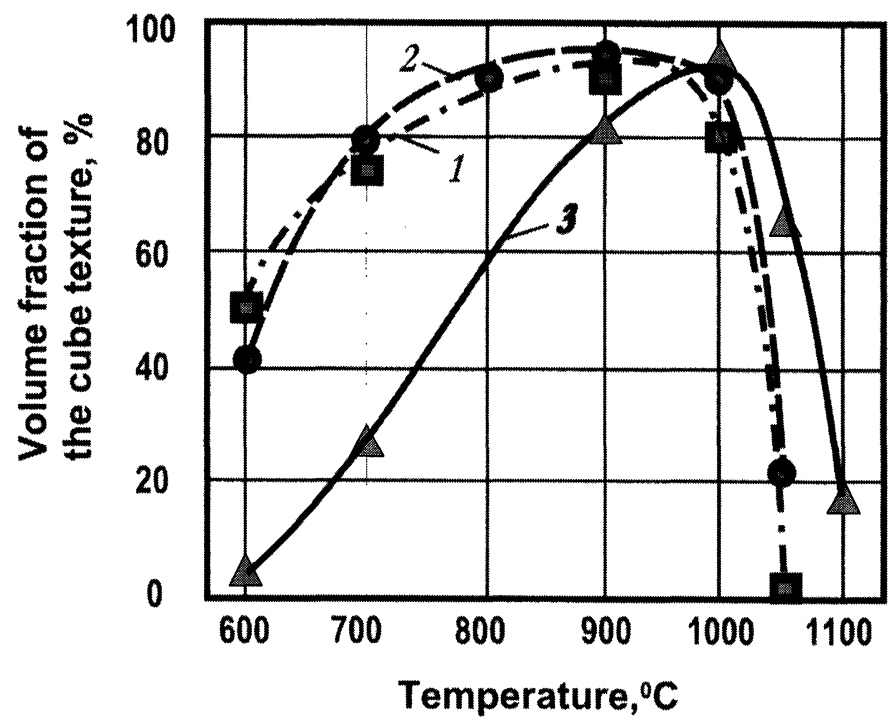

FIGURE 7 Dependence of the volume fraction of cubic component realized upon recrystallization on the annealing temperature. The rolling temperature: $1-\left(-196^{\circ} \mathrm{C}\right)$; $2-20^{\circ} \mathrm{C} ; 3-200^{\circ} \mathrm{C}$.

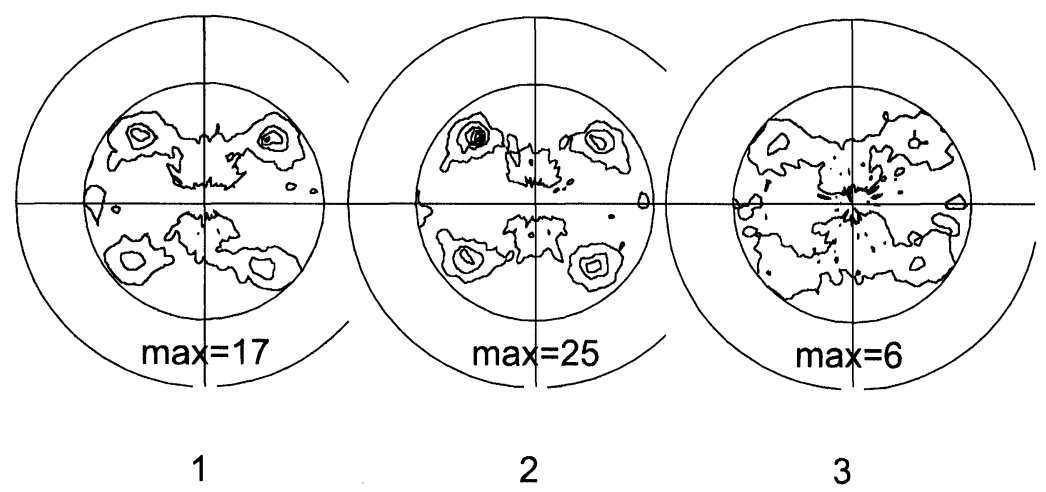

FIGURE 8 Pole figures $\{111\}$ after different-mode rolling (1,2 and 3) and rapid annealing in a salt bath at $800^{\circ} \mathrm{C}$.

The perfection degree of the cube texture was estimated from the halfwidth of the texture maximum $\{200\}$ along the directions RD and TD. The width of the texture maximum in these directions is different, 
it is always larger along the TD direction. The difference between the halfwidths of the maxima in the directions pointed is the smallest in the samples treated by mode 2 and the largest in the samples rolled at liquid nitrogen temperature.

Already at the initial stages of recrystallization (annealing at $400-$ $600^{\circ} \mathrm{C}$ ) in the mode 1 and 2 samples, there appear the sharp texture peaks $\{200\}$ whose halfwidth is not large (Fig. 9). With increasing annealing temperature, there occurs a certain increase in the halfwidth. The reason for this can be understood from of the structure pattern of the recrystallization development.

Figure 10 shows the microstructure of the sample that was rolled at room temperature and annealed at $250^{\circ}$. It is seen that in some structure bands, elongated in the rolling direction, there formed recrystallization grains. They are disposed in the form of chains parallel to TD (probably, they emerge on the shear bands). It is worth noting that the formation of the recrystallization grains proceeds solely in part of the deformation bands, whereas, in the others, recrystallization does not take place even at higher annealing temperatures. It is likely the first recrystallization grains that have the cubic orientation. The orientation of grains arisen later in the other structure areas may be somewhat declined from $\{100\}\langle 001\rangle$. The fact

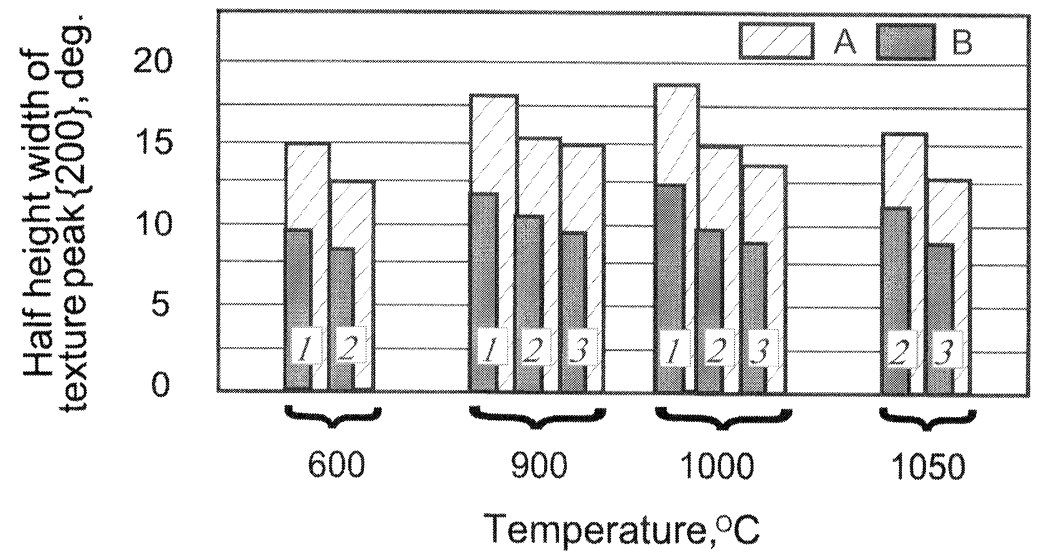

FIGURE 9 Dependence of the halfwidth of the texture maximum $\{200\}$ on the annealing temperature for the samples after different-mode rolling $(1,2$ and 3$)$. Ascattering around the rolling direction RD (along the TD); B-around the transverse direction TD (along the RD). 


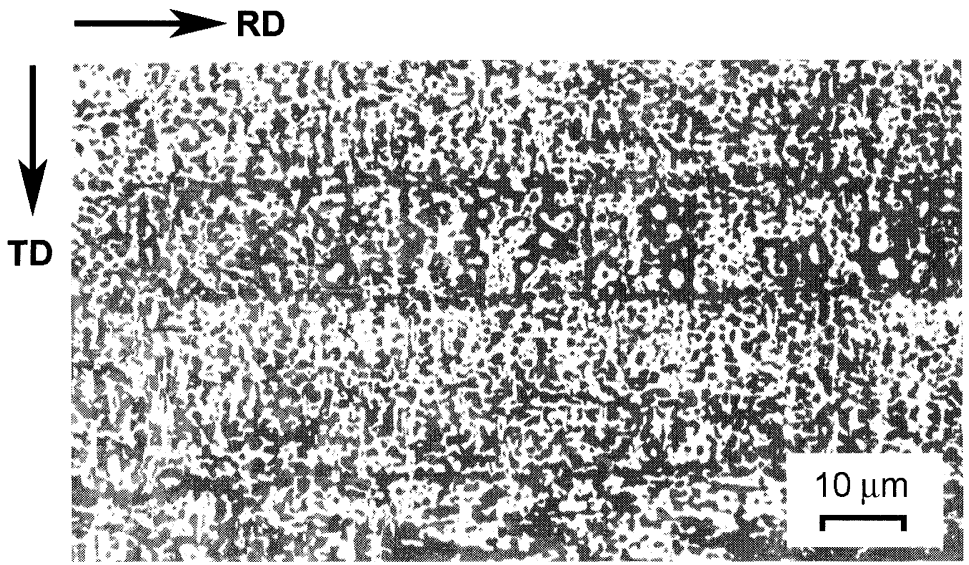

FIGURE 10 Microstructure of the sample rolled at room temperature and annealed at $250^{\circ} \mathrm{C}$.

that the formation of the recrystallization grains proceeds inhomogeneously is supported by the grain structure pattern obtained at a higher annealing temperature (Fig. 11). The grain colonies that have approximately equal size can be seen to form layers parallel to the rolling direction.

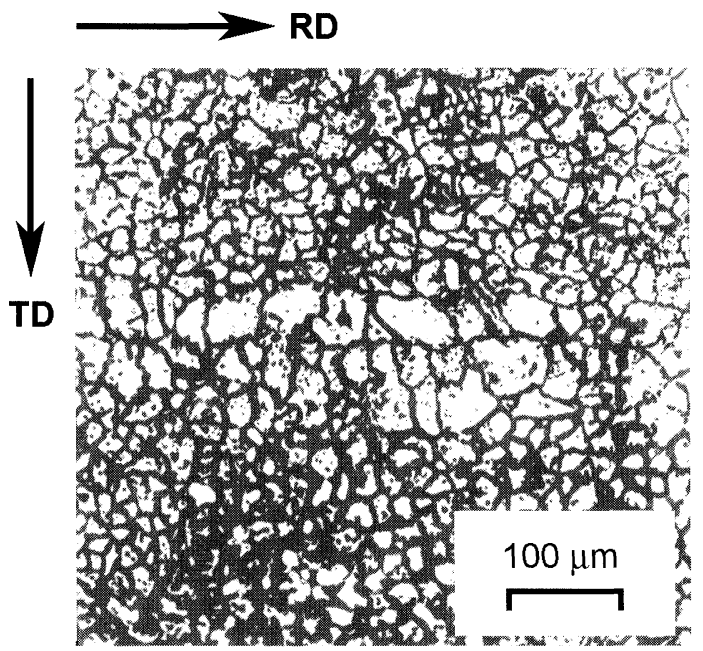

FIGURE 11 Microstructure of the sample rolled at $200^{\circ} \mathrm{C}$ and annealed at $900^{\circ} \mathrm{C}$. 
The dependence of the cube texture sharpness on the annealing temperature is ambiguous (Fig. 9). With elevating annealing temperature in the temperature interval $600-900^{\circ} \mathrm{C}$ the texture spread increases for the samples treated by modes 1 and 2 . In the interval of $900-1000^{\circ} \mathrm{C}$ for the mode 2 samples and $900-1050^{\circ} \mathrm{C}$ for the mode 3 samples the spread decreases and above $1000^{\circ} \mathrm{C}$, the spread increases for the mode 2 and continues to decrease for the mode 3 samples. An increase in the cube texture spread can be related to the onset of the secondary recrystallization. Indeed, in the samples discussed, an extremely coarse-grained irregular structure with curved boundaries and twins is formed at higher $\left(1050^{\circ} \mathrm{C}\right)$ temperatures (Fig. 12). Since, in the mode 3 samples, the secondary recrystallization starts at a higher annealing temperature, at 1000 and $1050^{\circ} \mathrm{C}$, an increase in the cube texture sharpness takes place.

In the samples under study, the average size of the matrix grains was determined at the annealing temperatures 900 and $1000^{\circ} \mathrm{C}$. In Table II, the results obtained are given.

With decreasing grain size, the temperature of the onset of secondary recrystallization lowers and, hence, a conclusion can be made that just as in the case of a pure material with sharp texture, the boundary energy of the matrix grains serves as a stimulus for the secondary recrystallization.

In pure nickel, twinning complicates the secondary recrystallization course. Figure 13 shows the observed unusual examples of the secondary recrystallization in the samples treated by mode 1 . In the fine-grained textured matrix, there arise twins that reach large sizes. Their growth proceeds mainly by migrating nonplanar twin

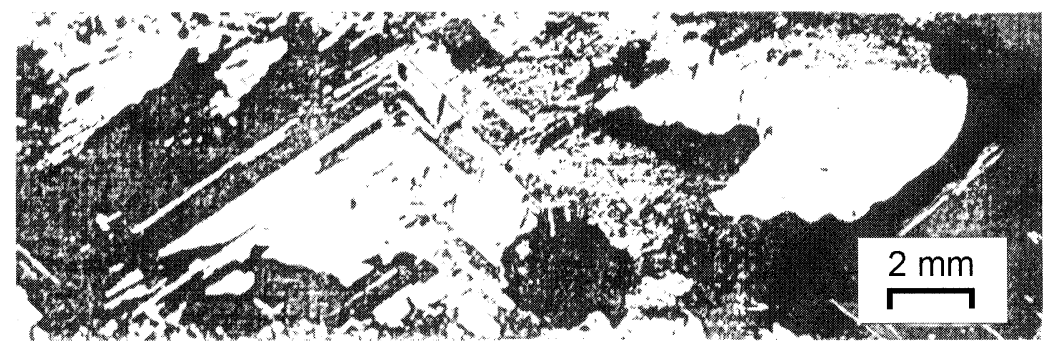

FIGURE 12 Structure of the secondarily recrystallized grains in the sample rolled at $-196^{\circ} \mathrm{C}$ and annealed at $1050^{\circ} \mathrm{C}$. 
TABLE II Average grain size $(\mu \mathrm{m})$ of the primarily recrystallized matrix after annealing at different temperatures and the temperature of the onset of secondary recrystallization

\begin{tabular}{|c|c|c|c|}
\hline \multirow[b]{2}{*}{ Mode of treatment } & \multicolumn{2}{|c|}{ Annealing temperature,${ }^{\circ} \mathrm{C}$} & \multirow{2}{*}{$\begin{array}{c}\text { Temperature of } \\
\text { onset of secondary } \\
\text { recrystallization, }{ }^{\circ} \mathrm{C}\end{array}$} \\
\hline & 900 & 1000 & \\
\hline 1 & $33 \pm 4$ & $52 \pm 5$ & 980 \\
\hline 2 & $38 \pm 4$ & $58 \pm 5$ & 1000 \\
\hline 3 & $45 \pm 6$ & $66 \pm 6$ & 1050 \\
\hline
\end{tabular}

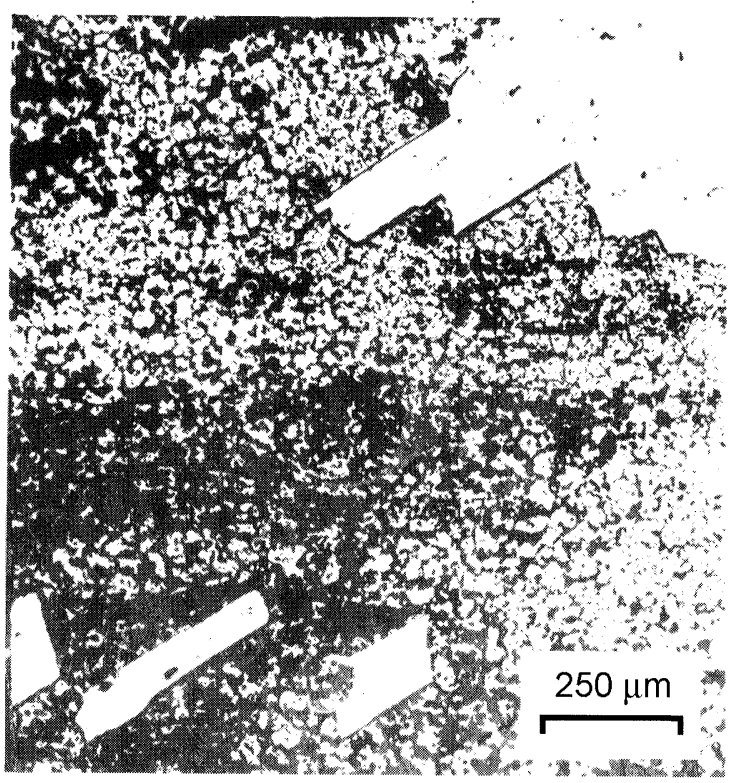

FIGURE 13 Twins in the fine-grained recrystallization matrix of the sample after rolling at $-196^{\circ} \mathrm{C}$ and annealing at $1000^{\circ} \mathrm{C}$.

boundaries. Note that twins in grains with a cubic orientation can be observed already at early stages of primary recrystallization (see Fig. 14).

The most developed grains of secondary recrystallization have orientations declined through angles $15-18^{\circ}$ from $\{100\}\langle 001\rangle$ $(\{130\}\langle 100\rangle ;\{115\}\langle 821\rangle ;\{10.2 .1\}\langle 012\rangle$ and others). Among them, there are twin orientations close to $\{221\}\langle 122\rangle$. 


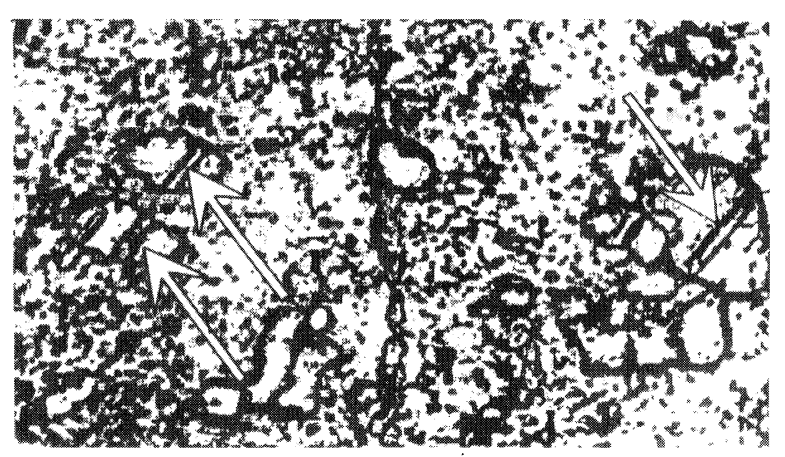

FIGURE 14 Twins formed in the primarily recrystallized grains upon roomtemperature rolling and annealing at $250^{\circ} \mathrm{C}$.

\section{DISCUSSION}

The influence of the roling temperature on the perfection of the cube texture upon recrystallization in pure nickel virtually has not been discussed in literature. As was already mentioned above, in (Makita, Hanada and Izumi, 1988) an idea was suggested that warm rolling should lead to improving the cube-texture perfection. However, experimentally, this suggestion was proved not quite correct. The results were compared at different annealing temperatures when in structures there occurred grains of secondary recrystallization.

When discussing the question about the temperature influence, the results can be taken into account that were obtained for other fcc metals - aluminum and copper. These metals, as well as nickel, have high stacking fault energy and their texture transformations upon annealing and deformation are alike.

In aluminum and copper, the rolling temperature below room temperature was shown to result in a decrease in the cubic component fraction in the recrystallization texture and to weaken its sharpness (Hu and Goodman, 1963; Wassermann and Grewen, 1969; Ridha and Hutchinson, 1982). In a number of works, this is considered to be caused by the fact that the deformation at a low temperature results in the formation of twins, although twinning is typical of deformation of fcc metals with low stacking fault energy. In such metals, upon deformation with a high degree, there arise mechanical twins of a small 
size $(0.02-0.2 \mu \mathrm{m})$. These twins affect the deformation texture, leading to the enhancement of the $\{111\}\langle\mathrm{uvw}\rangle$ component, and greatly influence the orientation of the recrystallization centers formed, decreasing the probability of the emergence of centers with orientation $\{100\}\langle 001\rangle$ significantly lowers.

The work (Ridha and Hutchinson, 1982) should be noted in which after rolling copper at $-196^{\circ} \mathrm{C}$, twins were not detected, although there arose a large number of shear bands which led to scattering the cube texture obtained. The conclusion was made in (Jasenski, Pospiech and Piatkowski, 1996) that shear bands could deteriorate the perfection of some deformation components and the cube texture upon recrystallization.

Our results on nickel do not display the presence of deformation twins after rolling at liquid nitrogen temperature either. The intensity of the main texture components of deformation in a subsurface layer of the samples turns out somewhat lower after rolling at liquid nitrogen temperature than after rolling at room temperature.

Spread of the cube recrystallization texture in the samples rolled at liquid nitrogen temperature is higher than in the case under comparison. So is the ratio of halfwidth of the texture peak measured along TD to that along RD.

It should be noted that at high annealing temperatures, in the samples treated in liquid nitrogen the grain size is less than in those rolled at room temperature and so is, consequently, the temperature of the onset of secondary recrystallization (Tab. II).

The microstructure pattern of the emergence of recrystallization centers shows that they are preferably formed on shear bands, however, nothing can be said about the number of shear bands in the samples differing in the rolling temperature.

There are many experimental data on fcc metals, aluminum and copper, confirming that with increasing deformation temperature, there take place a growth of the volume fraction of the cube texture and decrease of its spread (Wassermann and Grewen, 1969; Weiland and Hirsch, 1991; Lee, Lee and Ling, 1996; Vatne et al. and Higginson and Rate, 1999). This effect is explained in different ways. In (Vatne et al.) on pure aluminum the cubic orientation is stated to be more stable to deformation under rolling at high temperatures. The same viewpoint is advanced by the authors of study (Weiland and 
Hirsch, 1991) on aluminum alloy as well. In (Higginson and Rate, 1999), the enhancement of the cube texture upon annealing of warm rolled aluminum samples is related to the changes in the substructure of deformation bands. It leads to a distinguished substructure hindering of the recrystallization centers developed. The authors (Lee, Lee and Ling, 1996) found that upon increasing temperature of the compressive strain in copper, there increases the number of deformation bands, which should lead to a growth of the number of the arising cubic recrystallization centers. However, if at a certain deformation temperature, the dynamic recrystallization is getting on (a temperature above $300^{\circ} \mathrm{C}$ ), then the scattering of the cube texture increases and its volume fraction decreases. In our work on pure nickel, it was found that rolling at $200^{\circ} \mathrm{C}$ causes the emergence on the surface of the specific texture $\{100\}\langle 011\rangle$.

In the works on copper and aluminum (Lee and Duggan, 1991; Vatne, Daaland and Nes, 1994 and Choi et al., 1997) it was shown that the component $\{100\}\langle 011\rangle$ and also $\{111\}\langle 112\rangle$ and $\{111\}\langle 110\rangle$ are the main texture components obtained on the aluminum surface at an enhanced constant of friction between the tape and rolls. Hence, a conclusion can be made that the origin of the component $\{100\}\langle 011\rangle$, which is observed in the surface layer of the warm-rolled nickel, is traceable to increasing constant of the surface friction upon growing rolling temperature. Nevertheless this component is not detected in the samples that were rolled at room and lower temperatures, the difference in the texture content and the volume fraction of the main components still draws a conclusion that to produce a larger amount and larger perfection degree of the texture $\{100\}\langle 001\rangle$ one should remove a metal layer from the tape surface.

Rolling at a temperature of $200^{\circ} \mathrm{C}$ affects the structure and the kinetics of recrystallization. The deformation bands and shear bands are pronouncedly weaker than in the other samples. They got distorted because of the presence of certain substructure regions. In our opinion, warm rolling can cause a decrease in the number of shear bands arisen due to a less deformation hardening of a metal that results from the dynamic recovery. In the deformed structure one can observe large subgrains with a lower dislocation density that are contoured by welldefined boundaries. Although these subgrains may be potential recrystallization centers, their development proceeds very slowly, which 
contradicts the results (Higginson and Rate, 1999), which were obtained for the warm-rolled pure copper. The onset temperature for a noticeable growth of the recrystallization centers is higher in this case than that in the samples treated by other modes. All this can be accounted for by the development, during warm rolling, of dynamic recovery. After a high-temperature annealing of the warm-rolled samples the cube-texture scattering is less than that after the mode 1 and 2 treatments. However, the volume fraction of the cubic component in the texture of the warm-rolled samples is lower. The average size of the grains recrystallized upon annealing warm-rolled samples is higher than upon other deformation treatments. That is why the course of the secondary recrystallization is hindered and an opportunity of further growth of the volume fraction of the cubic component and of the texture improvement is afforded.

In our work it is shown that the scatter of the cube recrystallization texture can change with increasing annealing temperature both toward increasing and decreasing.

From the above results it follows that at early stage of recrystallization, the centers arise first that have an orientation close to the cubic $\{100\}\langle 001\rangle$. Scattering of the cube texture arisen is small when there are still a lot of surrounding grains belonging to the deformed matrix. Visible recrystallization centers form, as a rule, both on the boundaries (likely transition bands) and inside the deformation bands (on shear bands). It should be noted that such a formation proceeds by no means on all bands extended along RD. In a number of cases we observed almost complete recrystallization in some bands when in the others, recrystallization grains were still absent. The further recrystallization goes on both by the growth of the existing recrystallization grains into the surrounding bands and by the appearance and development in them of other recrystallization centers. This process usually proceeds with increasing scattering of the cube texture.

The appearance of secondary recrystallization is likely to be preceded by a certain increase in spread followed by a decrease in the volume fraction of the cube texture. The higher the temperature at which the secondary recrystallization takes place, the higher the opportunity of decreasing the cube-texture scattering.

Secondary recrystallization in nickel with a sharp cube texture has its own peculiarities. In pure nickel with a very low amount of 
impurities and no disperse phase-inhibitors, deceleration of normal grain growth is related solely to the so-called textural hindering of the grain growth. To keep in mind, the normal grain growth still proceeds (see Tab. II), though significantly poorer in comparison with the grain growth in pure non-textured metals. Deceleration of the normal grain growth gives rise to the growth of individual grains by the anomalous kinetics. It is these grains that are mostly declined from the cubic ones that may serve as centers of secondary recrystallization. Thus, in our case the developing secondary grains are mostly declined from (100)[001] by $15-18^{\circ}$. Similar results are described in (Makita, Hanada and Izumi, 1988). Unlike this work we noted the participation of twinning in the process of secondary recrystallization. In a finegrained textured matrix, we observed upon a high-temperature annealing the emergence of large-volume twins with planar boundaries, as well as the growth of these twinned elements predominantly from their curved boundaries. Other versions of the development of secondary recrystallization are possible as well. For instance, a twin arises on the boundary of the secondary recrystallization center developed and, as it has no twin orientation relative to the fine-grained textured matrix, it can grow into it rather fast.

The kinetics of secondary recrystallization in pure nickel greatly depends on the migration capacity of the grain boundaries that occur in the textured recrystallized matrix.

\section{CONCLUSIONS}

The results obtained in this work allows one to make a conclusion that the rolling temperature exerts influence both on the deformation texture and on the volume fraction of the cube component of the recrystallization texture and its scattering.

(1) Room-temperature rolling results in the realization of the maximum volume fraction of the main components of the deformation texture $\{110\}\langle 112\rangle$; $\{123\}\langle 634\rangle ;\{112\}\langle 111\rangle$ as compared with the other treatments. Upon annealing, a strong cube texture forms that is characterized by small scattering and low ratio of halfwidths of the texture maximum $\{200\}$ measured parallel and perpendicular RD. 
(2) Lowering the rolling temperature to $-196^{\circ} \mathrm{C}$ qualitatively does not change the deformation texture character, but the volume fraction of the main texture components is smaller. The scattering of the cube texture formed upon annealings is higher than that in the recrystallization texture of the samples rolled at room temperature, and the temperature of the onset of secondary recrystallization that cause the cube texture destruction is lower.

(3) Upon warm rolling of pure nickel, on the tape surface, there forms the friction texture that hampers the achievement of the perfect cube texture. The deformation texture in subsurface layers is similar to the texture of samples rolled at room temperature. Although the potential centers of recrystallization are formed already during warm rolling, the recrystallization rate is far less than that in the samples treated by other modes.

(4) The temperature of the onset of secondary recrystallization in samples after warm rolling is higher than that after other deformation treatments.

(5) Some specific features of the structure changes upon annealing of the deformed pure nickel are found. Primary recrystallization proceeds inhomogeneously, namely whereas in some bands elongated along RD, this process is almost completed, in the others it has not started yet. Large part of grains developed upon secondary recrystallization is grains formed from the twins.

\section{References}

Choi, C. H., Kwon, J. W., Oh, K. H. and Lee, D. N. (1997) Analysis of deformation texture inhomogeneity and stability condition of shear components in f.c.c. metals. Acta Mater., 45, 5119-5128.

De Boer, B., Reger, N., Opitz, R., Eickemeyer, J., Holzapfel, B. and Schultz, L. (1999) Recrystallised cold rolled nickel-alloys with a strong cube texture. In: Proc. of the ICOTOM-12, pp. 944-949. Ottawa: NRC Res. Press.

Gervasyeva, I. V., Rodionov, D. P., Sokolov, B. K., Khlebnikova, Yu.V. and Dolgih, D. V. (2000) Texture Evolution in Nickel during Rolling and Annealing Processes and Sharp Cube Texture Formation. The Metal Physics and Metallography, 90(3), 89-96.

Goyal, A., Norton, D. P., Budai, J. D., Paranthaman, M., Specht, E. D., Kroeger, D. M. et al. (1996) High critical current density superconductors tapes by epitaxial deposition of $\mathrm{YBa}_{2} \mathrm{Cu}_{3} \mathrm{O}_{\mathrm{x}}$ thick films on biaxially texturated metals. Appl. Phys. Lett., 69, 1795-1797.

Higginson, R. and Rate, P. (1999) Substructure drag effects and recrystallization textures in aluminium. Acta Mater., 47, 1079-1090. 
Hu, H. and Goodman, S. R. (1963) Texture transition in Copper. Transactions of the Metallurgical Society of AIME, 227, 627-639.

Jasienski, Z., Pospiech, J. and Piatkowski, A. (1996) Influence of the specific local misorientations within shear bands on the global rolling texture formation in polycrystalline copper and brass. In: Proc. of the ICOTOM-11, pp. 281-286. Beijing: International Academic Publishers.

Lee, C. S. and Duggan, D. J. (1991) A simple theory for the development of inhomogeneous rolling textures. Metall. Trans. A, 22A, 2637-2643.

Lee, C. S., Lee, C. F. and Ling, C. P. (1996) The influence of temperature on deformation banding and texture formation. In: Proc. of the ICOTOM-11, pp. 287-292. Beijing: International Academic Publishers.

Makita, H., Hanada, S. and Izumi, O. (1988) Recrystallization in cold-rolled pure nickel. Acta Metall., 36, 403-412.

Norton, D. P., Goyal, A., Budai, J. D., Christen, D. K., Kroeger, D. M., Specht, E. D. et al. (1996) Epitaxial $\mathrm{YBa}_{2} \mathrm{Cu}_{3} \mathrm{O}_{7}$ on Biaxially Textured Nickel (001): An Approach to Superconducting Tapes with High Critical Current Density. Science, 274, $755-757$.

Ridha, A. A. and Hutchinson, W. B. (1982) Recrystallization mechanisms and the origin of cube texture in copper. Acta Metall., 30, 1929-1939.

Specht, E. D., Goyal, A., Lee, D. F., List, F. A., Kroeger, D. M., Paranthaman, M. et al. (1998) Cube Textured Nickel Substrates for High-temperature Superconductors (HTSC). Supercond. Sci. Technol., 7, 945-949.

Vatne, H. E., Daaland, O. and Nes, E. (1994) On the formation of cube texture in aluminium. In: Proc. of the ICOTOM-10, Materials Sci. Forum, 157-162, $1087-1094$.

Vatne, H. E., Doherty, R. D., Bolingbroke, R. K. and Nes, E. (1996) Deformation and recrystallisation of hot deformed aluminium with high initial cube texture. In: Proc. of the ICOTOM-11, pp. 566-571. Beijing: International Academic Publishers.

Wassermann, G. and Grewen, J. (1969) Textures of Metal Materials. Moscow: Metallurgiya, $655 \mathrm{p}$. (Russian edition).

Weiland, H. and Hirsch, I. R. (1991) Microstructure and local texture in hot rolled aluminum. Textures and Microstructures, 14-18, 647-652.

Wu, X. D., Foltyn, S. R., Arendt, P., Townsend, J., Adams, C., Campbell, I. H. et al. (1994) High Current $\mathrm{YBa}_{2} \mathrm{Cu}_{3} \mathrm{O}_{7-\delta}$ thick films on flexible nickel substrates with textured buffer layers. Appl. Phys. Lett., 65, 1961-1963. 